\title{
Medication-overuse headache: an update
}

\author{
Paola Sarchielli \\ From Abstracts from the 1st Joint ANIRCEF-SISC Congress \\ Rome, Italy. 29-31 October 2015
}

Medication-overuse headache $(\mathrm{MOH})$ is a chronic daily headache evolving from an episodic primary headache (mainly migraine) due to overuse of one or more classes of migraine abortive medication.

The development of $\mathrm{MOH}$ is associated with both overuse of one or more medication and behavioral predispositions.

$\mathrm{MOH}$ causes a significant decline in the quality of life and reduces functioning in patients affected. In the same $\mathrm{MOH}$ patients, the presence of psychopathological disturbances may be a predictor of relapse and poor response to treatment.

In a recent study of our group, we found that $\mathrm{MOH}$ patients had a more complex profile of psychiatric comorbidity compared to episodic migraine (EM) patients. Furthermore, clinically relevant obsessive-compulsive disturbances for abused drugs assessed by Yale-Brown Obsessive Compulsive Scale Y-BOCS, appeared to be more represented in the $\mathrm{MOH}$ group, while the prevalence of this trait in the EM group was comparable to that of healthy controls (unpublished results).

Management of $\mathrm{MOH}$ represents a difficult challenge for clinicians and headache experts, particularly because of the high percentage of relapse after a successful withdrawal treatment.

This can be addressed if the patient is followed over a prolonged period of time with a combination of prophylactic pharmacotherapy and use of abortive medication with minimal risk of $\mathrm{MOH}$, avoiding previously overused medications.

With the aim to verify the efficacy and safety of sodium valproate in the short-term treatment of $\mathrm{MOH}$, we recently carried out a multicentre study (SAMOHA study) which demonstrated a superiority of the drug compared to placebo after detoxification [1].

Correspondence: paola.sarchielli@unipg.it

Clinica Neurologica, Azienda Ospedaliero - Universitaria di Perugia, Perugia, Italy

\section{SpringerOpen ${ }^{\circ}$}

C 2015 Sarchielli This is an Open Access article distributed under the terms of the Creative Commons Attribution License (http:// creativecommons.org/licenses/by/4.0), which permits unrestricted use, distribution, and reproduction in any medium, provided the original work is properly cited. The Creative Commons Public Domain Dedication waiver (http://creativecommons.org/publicdomain/ zero/1.0/) applies to the data made available in this article, unless otherwise stated.
In an ancillary study of SAMOHA, analysing responders and non responders to detoxification and advice to withdraw a benefit was excluded in patients with a long history of $\mathrm{MOH}$ [2].

In a further ancillary research we found a significant correlation between $\mathrm{MOH}$ relapse and the total MSQ score, the Role Preventive and the Emotional Function sub-scales, suggesting a poorer quality of life in non responders [3].

Recent evidence suggests an involvement of genetic factors in predisposition to medication overuse. In a recent study of our group involving a subsample of $\mathrm{MOH}$ patients enrolled in the SAMOHA study, we sequenced all exons, intron/exon junctions and 3'-5'UTR regions of HDAC3 gene which had been implicated in excessive medication consumption in $\mathrm{MOH}$ patients. Univariate analysis showed that the G allele of the exonic SNP rs2530223 was significantly associated with the number of acute medications/month used and with the number of days/month in which acute medication were used (unpublished results).

Published: 28 September 2015

\section{References}

1. Sarchielli P, Messina P, Cupini LM, Tedeschi G, Di Piero V, Livrea P, Pini LA, Bernardi G, Bono G, Sandrini G, Caproni S, Corbelli I, Pisani F, Beghi E, Calabresi $P$, for SAMOHA study group: Sodium valproate in migraine without aura and medication overuse headache: $A$ randomized controlled trial. Eur Neuropsychopharmacol 2014, 24:1289-1297.

2. Caproni S, Bianchi E, Cupini LM, Corbelli I, Beghi E, Calabresi P, Sarchielli P, for SAMOHA study group: Long term headache duration is a factor predicting non response $t$ o detoxification and advice in medication overuse headache. J Headache Pain 2014, 15:88.

3. Caproni S, Bianchi E, Cupini LM, Corbelli I, Beghi E, Calabresi P, Sarchielli P, for SAMOHA study group: Migraine-specific quality of life questionnaire and relapse of medication overuse headache. BMC Neurol 2015, 15:85.

doi:10.1186/1129-2377-16-S1-A46

Cite this article as: Sarchielli: Medication-overuse headache: an update. The Journal of Headache and Pain 2015 16(Suppl 1):A46. 